BMJ Open Diabetes Research \& Care

\title{
Impaired exocrine pancreatic function in different stages of type 1 diabetes
}

Nicoletta Dozio, ${ }^{1,2,3}$ Rita Indirli (1) , ${ }^{1,3}$ Gian Maria Giamporcaro, ${ }^{3}$ Laura Frosio, ${ }^{1,3}$ Alessandra Mandelli (iD ,2 Andrea Laurenzi, ${ }^{2,3}$ Andrea Mario Bolla (1) ,,3 Angela Stabilini, ${ }^{2}$ Andrea Valle, ${ }^{2}$ Massimo Locatelli, ${ }^{4}$ Giulia Martina Cavestro, ${ }^{5}$ Marina Scavini, ${ }^{2,3}$ Manuela Battaglia, ${ }^{2}$ Emanuele Bosi ${ }^{1,2,3}$

\section{ABSTRACT}

Giamporcaro GM, et al. Impaired exocrine pancreatic function in different stages of type 1 diabetes. BMJ Open Diab Res Care 2021;9:e001158. doi:10.1136/ bmjdrc-2019-001158

- Supplemental material is published online only. To view, please visit the journal online (http://dx.doi.org/10.1136/ bmjdrc-2019-001158).

$M B$ and $E B$ contributed equally.

ND and RI are joint first authors.

Received 26 December 2019 Revised 3 September 2020 Accepted 18 January 2021

Check for updates

(c) Author(s) (or their employer(s)) 2021. Re-use permitted under CC BY-NC. No commercial re-use. See rights and permissions. Published by BMJ.

${ }^{1}$ Vita-Salute San Raffaele University, Milan, Italy ${ }^{2}$ Diabetes Research Institute, IRCCS San Raffaele Hospital, Milano, Italy

${ }^{3}$ Department of General Medicine, Diabetes \&

Endocrinology, IRCCS San Raffaele Hospital, Milano, Italy ${ }^{4}$ Department of Laboratory Medicine, IRCCS San Raffaele Hospital, Milano, Italy ${ }^{5}$ Gastroenterology and Endoscopy Unit, IRCCS San Raffaele Hospital, Milano, Italy

Correspondence to Dr Emanuele Bosi; bosi.emanuele@hsr.it
Introduction Aim of this study was to investigate the pancreatic exocrine function in patients with type 1 diabetes (T1D) by multiple non-invasive tests.

Research design and methods The study is a singlecenter, cross-sectional study of pancreatic exocrine function in adult patients with new-onset or long-standing T1D and healthy controls.

Results Healthy controls, new-onset T1D, and long-standing T1D were similar for age at the time of the study, gender and body mass index (BMI) categories. Age of onset of T1D patients with long-standing disease was younger than that of patients with new-onset T1D $(p<0.001)$. As expected, the three groups differed for $\mathrm{C}$-peptide and hemoglobin A1c ( $\mathrm{HbA1c}$ ) levels. Lipase activity measured by ${ }^{13} \mathrm{C}$-mixed triglyceride breath test was reduced progressively, although not significantly, from controls to recent-onset T1D and longstanding T1D participants. Fecal elastase-1 was significantly lower in participants with T1D, either new onset or long standing. Pancreatic amylase, lipase, retinol binding protein and prealbumin were significantly different across the groups, with a significant trend toward lower values in long-standing T1D and intermediate values in new-onset T1D, while no differences were observed for total amylase. The markers of impaired exocrine function tests (fecal elastase-1, serum pancreatic amylase and lipase) and of nutritional status (retinol binding protein and prealbumin levels) correlated with the reduction of fasting and urinary C-peptide.

Conclusions Our results confirm that exocrine pancreatic impairment is a feature of T1D, with low fecal elastase-1, serum pancreatic amylase and lipase as specific markers, associated with reduced levels of nutritional indexes. Moreover, the evidence of more advanced insufficiency in long-standing disease reflects the chronic nature of this process, and its correlation with the residual $\beta$-cell function suggests parallel pathways for the impairment of the endocrine and exocrine pancreatic function.

\section{INTRODUCTION}

Type 1 diabetes (T1D) is a chronic autoimmune disease in which insulin producing $\beta$-cells are selectively destroyed within pancreatic islets. ${ }^{1}$ Not surprisingly, studies on the pathogenesis and pathophysiology of T1D have been focused on $\beta$-cells and other islet cells, based on the assumption that the endocrine pancreas is a functional structure

\section{Significance of this study}

What is already known about this subject?

- Several studies in the past decades have reported impaired exocrine pancreatic function in patients with diabetes, especially type 1 diabetes (T1D).

What are the new findings?

- We confirm that exocrine pancreatic impairment is a feature of T1D, with low fecal elastase-1, serum pancreatic amylase and lipase as specific markers using non-invasive methods. We found more advanced insufficiency in long-standing T1D as to reflect the progressive nature of the process.

- In patients with T1D, there are low fecal elastase-1, serum pancreatic amylase and lipase.

- There is more advanced pancreatic exocrine insufficiency in long-standing T1D as to reflect the progressive nature of the process.

- There is a correlation between the progressive impairment of exocrine and endocrine pancreatic function along the natural history of T1D.

- Research for mechanisms responsible for T1D should include the exocrine pancreas as target organ.

How might these results change the focus of research or clinical practice?

- The correlation of exocrine pancreatic impairment with residual $\beta$-cell function suggests associated and maybe interdependent mechanisms underlying disease progression.

separated from, although anatomically embedded in, the exocrine pancreas. ${ }^{2}$

Investigations on the possible interactions between diabetes-associated islet abnormalities and pancreatic exocrine function date back decades ago, showing different degrees of exocrine dysfunctions, generally with marginal, if any, clinical impact. ${ }^{3-10}$

The subsequent availability of indirect tests for measuring exocrine pancreatic function, such as fecal elastase $1,{ }^{11}$ allowed the conduction of larger studies, which demonstrated 
an excess of impaired exocrine pancreatic function in patients with diabetes, especially T1D. ${ }^{12}$

In recent years, the involvement of the exocrine component of the pancreas in the pathogenesis of T1D has been revisited, based on the accumulation of evidence, including reduction of pancreatic volume, ${ }^{10}{ }^{13-15}$ and estimated weight, ${ }^{16} 17$ intraparenchymal neutrophil and monocyte infiltration, ${ }^{18-20}$ peri-islet fibrosis and acinar atrophy, ${ }^{21}$ reduction of circulating trypsinogen ${ }^{22}$ and trypsin, ${ }^{8}$ and altered amylase expression patterns. ${ }^{23}$ Interestingly, many of these abnormalities were observed already during the presymptomatic phase of the disease, that is, in individuals with normal glucose tolerance, although positive for circulating islet autoantibodies, ${ }^{15-172022} 23$ suggesting that these features are associated with the pathogenesis of T1D, rather than secondary to its metabolic abnormalities.

The non-invasive assessment of the pancreatic exocrine function is possible, although mild and subclinical alterations remain difficult to document. ${ }^{24}$ The aim of this study was to investigate pancreatic exocrine function in patients with T1D using different indirect diagnostic tests, including the dynamic ${ }^{13} \mathrm{C}$-mixed triglyceride breath test, the measurement of fecal elastase-1, fasting serum pancreatic amylase and lipase, as well as markers of nutritional status, in comparison with matched healthy control individuals. Patients with T1D included two groups, recently diagnosed and long standing, with the objective of characterizing potential abnormalities, also with respect to the natural course of disease.

\section{RESEARCH DESIGN AND METHODS}

\section{Study design}

The study is a single-center, cross-sectional study of pancreatic exocrine function in adult patients with newonset or long-standing T1D and age-matched healthy controls. All participants signed an informed consent prior to their screening visit.

\section{Study participants}

The following group subjects were enrolled in the study: adult ( $\geq 18$ years of age) patients with a diagnosis of T1D according to the American Diabetes Association, ${ }^{25}$ subdivided into two subgroups: recent onset: having been diagnosed and treated with insulin for less than 4 months, with positivity for at least one islet autoantibody among GADA, IAA, IA2A and ZnT8A; and long standing: with established disease for at least 5 years or longer, also screened, but not necessarily positive for islet autoantibodies; and matched healthy volunteers, negative for islet autoantibodies. Exclusion criteria included: symptomatic or active gastroenteric diseases; medications acting on the digestive system (including prokinetic or anticholinergic agents); possible severe pancreatic exocrine insufficiency according to the Italian Gastroenterological Society standardized questionnaire ${ }^{26}$; and known nut allergy.

\section{Exocrine pancreatic function tests}

Exocrine pancreatic function was assessed by the following measurements.

Lipase activity was assessed in vivo by the dynamic ${ }^{13} \mathrm{C}$ mixed triglyceride breath test (MTGT), performed after an overnight fast. ${ }^{27}$ Participants were instructed to avoid foods naturally enriched in ${ }^{13} \mathrm{C}$ (like pineapple, corn and cane sugar) during the 48 hours preceding the test. The

${ }^{13} \mathrm{C}$-labeled triglycerides (1,3-distearyl, 2 [carboxyl $-{ }^{13} \mathrm{C}$ ] octanoyl glycerol) were mixed with $30 \mathrm{~g}$ of a chocolate and nut paste and spread on $25 \mathrm{~g}$ of gluten-free crackers. Expired air was collected before consumption of the standardized fat meal and every $30 \mathrm{~min}$ for 4 hours thereafter. The ${ }^{13} \mathrm{C}$ content of the expired air was measured by mass spectrometry and expressed as hourly and cumulative percent recovery of the ingested dose, providing an indirect estimate of pancreatic lipase activity (AB Analitica, Padua, Italy; normal pancreatic lipase activity $>30 \%$ ).

Fecal elastase-1 concentration was measured on a fecal sample collected by patients at home in the 24 hours preceding the breath test. A highly sensitive, two monoclonal antibody-based ELISA for human duodenal and fecal elastase-1 was used for the assay (ScheBo Biotech AG, Giessen, Germany). Concentrations of fecal elastase $1>200 \mu \mathrm{g} / \mathrm{g}$ of feces were considered normal; concentrations ranging between 100 and $200 \mu \mathrm{g} / \mathrm{g}$ were indicative of mild-to-moderate pancreatic insufficiency, whereas severe pancreatic insufficiency was defined by levels below $100 \mu \mathrm{g} / \mathrm{g}$.

Serum total and pancreatic amylase and lipase concentrations were measured on morning fasting venous blood samples by automated methods (Roche Diagnostics GmbH, Mannheim, Germany: IFCC PNP-G7 for total amylase, reference range 28-100 U/L; immunoinhibition for pancreatic amylase, reference range $13-53 \mathrm{U} / \mathrm{L}$; and enzymaticcolorimetric method for lipase, reference range $0-60 \mathrm{U} / \mathrm{L})$.

\section{Markers of nutritional status}

The followings were measured: serum prealbumin (turbidimetric method; reference range $0.2-0.4 \mathrm{~g} / \mathrm{L}$; Roche Diagnostics $\mathrm{GmbH}$ ), retinol binding protein (turbidimetric method; reference range 15-67 mg/L; Optilite Binding Site, Birmingham, UK), and ferritin (electrochemiluminescence; reference range 30-400 $\mu \mathrm{g} / \mathrm{L}$; Roche Diagnostics GmbH). Vitamin D was not included as a marker due to the high prevalence of subclinical vitamin D deficiency in the general population of Northern Italy. ${ }^{28}$

\section{Endocrine pancreatic function tests}

Serum fasting C-peptide was measured by ElectroChemiluminescent Assay, CLIA, on automatic Instrumentation Cobas 8000 (Roche Diagnostics GmbH).

Urinary C-peptide was measured on spot urine using Ultrasensitive C-peptide ELISA cat. 10-1141-01 (Mercodia AB, Uppsala, Sweden). Serum fasting C-peptide and spot urinary C-pepitde were highly correlated $(\mathrm{p}<0.001)$. 
Table 1 General characteristics of study participants, by group

\begin{tabular}{|c|c|c|c|c|}
\hline & Controls & New-onset T1D & Long-standing T1D & P value \\
\hline $\mathrm{N}$ & 25 & 12 & 19 & \\
\hline Age (years) & $28(24-31)$ & $25(18-36)$ & $30(20-38)$ & 0.6414 \\
\hline Gender female (\%) & $11(44.0)$ & $3(23.1)$ & $12(63.2)$ & 0.0760 \\
\hline Age at T1D onset (year) & - & $25(18-36)$ & $14(9-23)$ & 0.0035 \\
\hline Disease duration & - & 36 days $(29-89)$ & 13.5year (9.6-18.1) & $<0.0001$ \\
\hline BMI $\left(k g / m^{2}\right)$ & $24.1(22.4-26.4)$ & $20.7(19.5-22.2)$ & $22.8(21.1-23.8)$ & $0.0166^{\star}$ \\
\hline $\mathrm{BMI} \leq 18.49 \mathrm{~kg} / \mathrm{m}^{2}$ & 0 & 0 & 1 & 0.3711 \\
\hline $18.50 \leq \mathrm{BMI} \leq 24.99 \mathrm{~kg} / \mathrm{m}^{2}$ & 15 & 10 & 15 & 0.2277 \\
\hline $25 \leq \mathrm{BMI} \leq 29.99 \mathrm{~kg} / \mathrm{m}^{2}$ & 6 & 2 & 2 & 0.5089 \\
\hline $\mathrm{BMI} \geq 30.0 \mathrm{~kg} / \mathrm{m}^{2}$ & 4 & 0 & 1 & 0.2200 \\
\hline Fasting C-peptide (ng/mL) & $1.43(1.17-1.64)$ & $0.77(0.36-1.09)$ & $0.20(0.20-0.20)$ & $0.0001 \dagger$ \\
\hline Plasma glucose (mg/dL) & 72 (67-79) & $114(85-120)$ & $89(74-155)$ & $0.0001 \ddagger$ \\
\hline HbA1c (mmol/mol) & $31(29-33)$ & $64(48-76)$ & $56(53-59)$ & $<0.0001 \S$ \\
\hline
\end{tabular}

Continuous variables are presented as median and IQR in parentheses; categorical variables are presented as frequency and per cent in parentheses.

${ }^{*} \mathrm{P}=0.0077$ : new-onset T1D versus controls; $p=0.1431$ : long-standing T1D versus controls; $p=0.0962$ : new-onset T1D versus long-standing T1D.

$\dagger P=0.0002$ : new-onset T1D versus controls; $p<0.0001$ : long-standing T1D versus controls; $p<0.0001$ : new-onset T1D versus long-standing T1D.

$\ddagger P<0.0001$ : new-onset T1D versus controls; $p=0.0010$ : long-standing T1D versus controls; $p=0.1320$ : new-onset T1D versus long-standing T1D.

$\S \mathrm{P}<0.0001$ : new-onset T1D versus controls; $p<0.0001$ : long-standing T1D versus controls; $p=0.3373$ : new-onset T1D versus long-standing T1D.

BMI, body mass index; HbA1c, hemoglobin A1c; T1D, type 1 diabetes.

Fasting plasma glucose, glycated hemoglobin, complete blood count, serum lipid profile, inflammatory markers, magnesium, renal and liver function tests, and fecal calprotectin were measured by standard laboratory assays.

\section{Statistical analysis}

Statistical analysis was performed using STATA V.11.0. Categorical variables are presented as frequencies and percentages. The Shapiro-Wilk test and box plots were used to investigate distributions of quantitative variables. Normally distributed continuous variables were presented as mean $\pm \mathrm{SD}$ and compared using analysis of variance or unpaired Student's t-test, as appropriate. Non-normally distributed continuous variables are presented as median and IQR and compared using Kruskal-Wallis test or Mann-Whitney test, as appropriate. Correlation between normally distributed variables was tested by Pearson correlation coefficient; when non-normally distributed variables were considered, Spearman's rank correlation test was used. A two-sided $\mathrm{p}$ value $<0.05$ was considered statistically significant.

\section{RESULTS}

\section{Demographic and clinical characteristics}

Demographics and clinical characteristics of study participants are summarized in table 1 .

The three groups of participants (healthy controls, new-onset T1D, and long-standing T1D) did not differ for age at the time of the study, proportion of females and BMI categories. Groups were similar also for total cholesterol, HDL cholesterol, liver function tests, creatinine and CRP (data not shown). The age of onset of T1D patients with long-standing disease was younger than that of patients with new-onset T1D $(\mathrm{p}<0.001)$, since our study was approved for adult patients only. As expected, the three groups differed for C-peptide and HbA1c levels. The islet autoantibody profile of study participants is reported in online supplemental table 1; although positivity for islet autoantibodies was not an inclusion criterion for long-standing T1D patients due to the fact that autoantibodies may become undetectable after disease onset, 18 out of 19 of them had one or more persistent autoantibodies, making the two T1D subgroups homogeneous with regard to their islet autoantibody status.

\section{Pancreatic exocrine function and selected nutritional indexes}

Pancreatic exocrine function and selected nutritional indexes are reported in table 2 and figure 1.

On average, pancreatic exocrine function tests in both healthy controls and T1D participants were within the normal reference range, as expected since we excluded individuals with possible severe pancreatic exocrine insufficiency. Lipase activity measured by ${ }^{13} \mathrm{C}$-mixed triglyceride breath test showed a trend, although not statistically significant, towards a reduction going from controls to recent-onset T1D and long-standing T1D participants. Fecal elastase-1 was significantly lower in 
Table 2 Pancreatic exocrine function and selected nutritional indexes, by group

\begin{tabular}{lllll}
\hline & Controls & New-onset T1D & Long-standing T1D & P value \\
\hline $\mathrm{N}$ & 25 & 12 & 19 & \\
Lipase activity $(\%)$ & $121.3(93.7-175.5)$ & $118.8(88.8-143.0)$ & $116.7(87.4-141.4)$ & 0.4893 \\
\hline Fecal elastase $(\mathrm{\mu g} / \mathrm{g})$ & $500(500-500)$ & $474(353.5-500)$ & $380(281-500)$ & $0.0020 \S$ \\
\hline Total amylase $(\mathrm{U} / \mathrm{L})$ & $65(54-76)$ & $63(35-86)$ & $50(39-74)$ & 0.1293 \\
Pancreatic amylase (U/L) & $28(23-35)$ & $25(14-41)$ & $18(14-21)$ & 0.00139 \\
Lipase (U/L) & $30(25-33)$ & $26(21-39)$ & $22(19-26)$ & $0.0106^{*}$ \\
Retinol binding protein (g/L) & $0.042(0.035-0.047)$ & $0.037(0.035-0.042)$ & $0.031(0.025-0.034)$ & $0.0002 \dagger$ \\
Prealbumin (g/L) & $0.28(0.24-0.32)$ & $0.26(0.25-0.29)$ & $0.20(0.18-0.22)$ & $0.0001 \ddagger$ \\
\hline
\end{tabular}

Continuous variables are presented as median and IQR in parentheses; categorical variables are presented as frequency and per cent in parentheses.

${ }^{*} \mathrm{P}=0.5482$ : new-onset T1D versus controls; $p=0.0019$ : long-standing T1D versus controls; $p=0.1149$ : new-onset T1D versus long-standing T1D (test for trend: $\mathrm{p}=0.037$ ).

$\dagger P=0.4062$ : new-onset T1D versus controls; $p=0.0001$ : long-standing T1D versus controls; $p=0.0042$ : new-onset T1D versus long-standing T1D (test for trend: $p=0.002$ ).

$\ddagger P=0.5761$ : new-onset T1D versus controls; $p<0.0001$ : long-standing T1D versus controls; $p=0.0001$ : new-onset T1D versus long-standing T1D (test for trend: $p<0.0001)$.

$\S \mathrm{P}=0.0070$ : new-onset T1D versus controls; $p=0.0010$ : long-standing T1D versus controls; $p=0.2362$ : new-onset T1D versus long-standing T1D (test for trend: $\mathrm{p}=0.199$ ).

१P=0.5203: new-onset T1D versus controls; $p=0.0001$ : long-standing T1D versus controls; $p=0.1825$ : new-onset T1D versus long-standing T1D (test for trend: $p=0.014$ ).

T1D, type 1 diabetes.

participants with T1D, either new onset or long standing. Pancreatic amylase, lipase, retinol binding protein and prealbumin were significantly different across the groups, with a significant trend towards lower values in long-standing T1D and intermediate values in new-onset T1D, while no differences between the three groups were observed for total amylase. None of the remaining variables showed differences across the three groups of participants.

The reductions of fecal elastase-1, serum pancreatic amylase and lipase were highly correlated with the reduction of fasting and urinary $\mathrm{C}$-peptide (all $\mathrm{p}<0.001$ ), while no correlation was found with lipase activity. The markers of nutritional status retinol binding protein and prealbumin were also highly correlated with serum fasting and urinary C-peptide (all p<0.001).

\section{DISCUSSION}

Abnormalities of the pancreatic exocrine function in T1D have recently received renewed attention, because of their potential role in the pathogenesis of the disease, ${ }^{13-23}$ having been detected also during the presymptomatic phase of T1D, that is, in islet autoantibody positive individuals. ${ }^{15-1720-23}$

Our findings confirm the evidence of some degree of impairment of the pancreatic exocrine function in patients with T1D, compared with healthy controls. Lipase activity was reduced as a non-significant trend when measured by the ${ }^{13} \mathrm{C}$-mixed triglyceride breath test, while functional insufficiency was more manifest and significant when reflected by the reduction of fecal elastase-1 and serum pancreatic amylase and lipase.
Moreover, some markers of nutritional status, such as retinol binding protein and prealbumin, were also found to be reduced in T1D study participants.

Subclinical abnormalities of the exocrine function are difficult to measure, and this may explain why their detection in patients with T1D has been neglected for so long. ${ }^{24}$ None of the non-invasive pancreatic function tests is sensitive enough to diagnose mild to moderate exocrine pancreatic insufficiency ${ }^{29}$; fecal elastase-1 currently is the most used test for screening pancreatic exocrine insufficiency, ${ }^{30}$ with ${ }^{13} \mathrm{C}$-mixed triglyceride breath test being an alternative, which has become widely used in recent times because of its simplicity and safety. ${ }^{2731}$

Our study shows a significant reduction of fecal elastase-1 in T1D compared with healthy controls, progressing from new-onset to long-standing patients, while ${ }^{13} \mathrm{C}$-mixed triglyceride breath test showed a reduction, although not significant, of lipase activity. In addition, serum pancreatic amylase and lipase were reduced in T1D study participants, with no changes in total amylase. Low serum pancreatic enzymes have long been observed in patients with diabetes, particularly those with T1D, ${ }^{568932}$ but only recently they have been accepted as highly specific markers of chronic pancreatic insufficiency in subjects without diabetes. ${ }^{33}$ Our findings in adult patients with T1D are consistent with those reported in children ${ }^{34}$ and reinforce the evidence of the presence of exocrine pancreatic abnormalities in patients with T1D. Regrettably, the reduction of lipase activity as measured by ${ }^{13} \mathrm{C}$-mixed triglyceride breath test was not statistically significant, possibly because of its relative low specificity, as previously reported. ${ }^{36}$ 

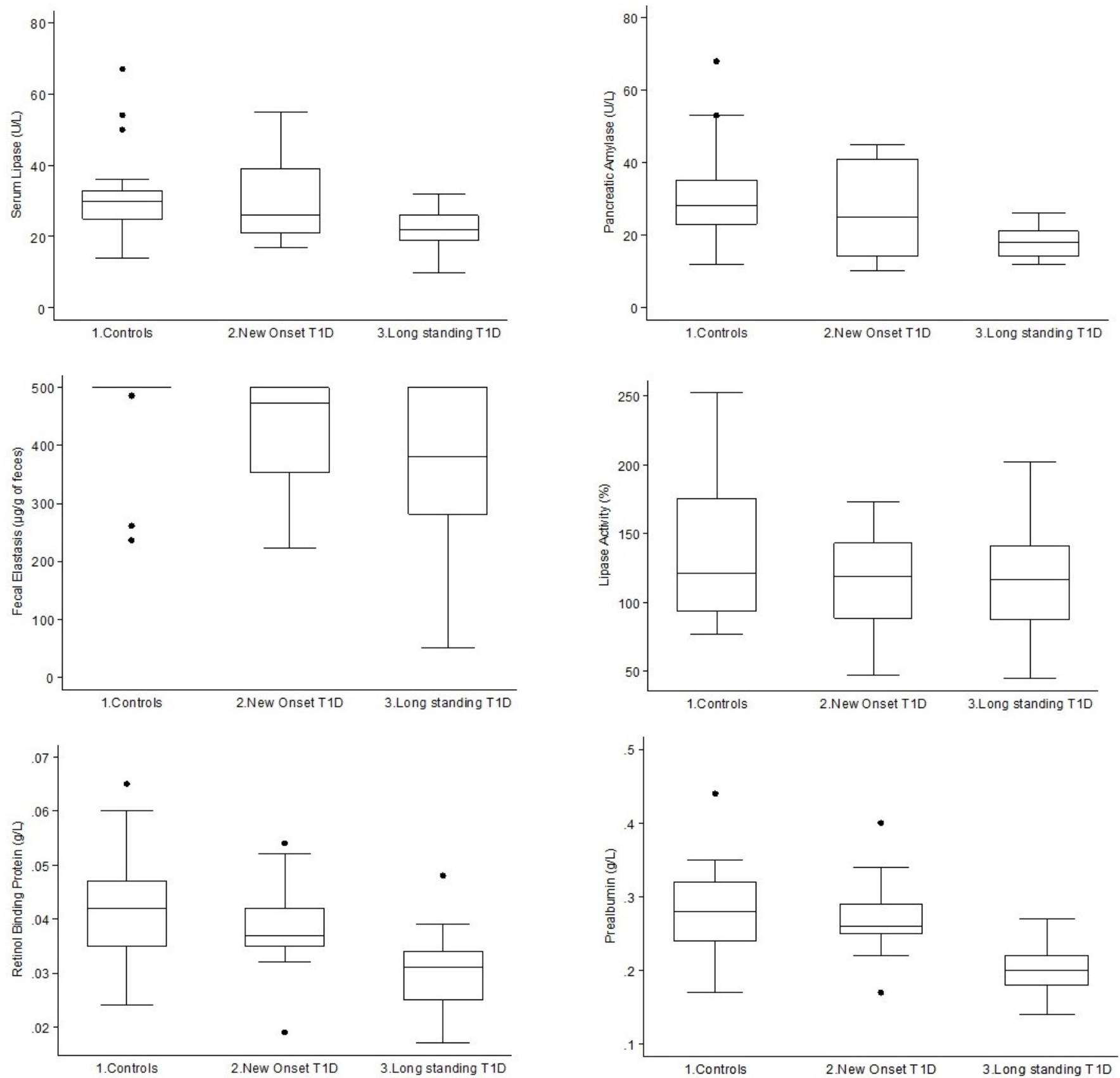

Figure 1 Serum lipase (upper left panel), pancreatic amylase (upper right panel), fecal elastase (middle left panel), lipase activity (middle right panel), retinol binding protein (lower left panel) and prealbumin (lower right panel), by group. T1D, type 1 diabetes.

The subgroup analysis of patients with T1D according to the duration of disease showed more marked abnormalities in long standing than new onset, consistently with a progressive worsening of pancreatic exocrine insufficiency along the course of the disease. Since the natural history of exocrine pancreas abnormalities in T1D is not known, considering that the earliest evidence of exocrine pancreatic abnormalities have been shown already during the presymptomatic phase of T1D,${ }^{15-1720-23}$ it is likely that exocrine pancreatic dysfunction develops and persists during the whole natural history of T1D.
An additional finding is the correlation of exocrine pancreatic insufficiency with residual C-peptide levels, already reported in the past in two studies, ${ }^{937}$ suggesting that changes in endocrine pancreatic function progress in parallel with those of the exocrine pancreatic function, possibly reflecting some similar mechanisms between the two associated pathogenetic patterns.

The finding of lower concentrations of retinol binding protein and prealbumin in T1D compared with healthy controls confirms a previous observations in the contest of uncontrolled disease, ${ }^{38} 39$ and their association with 
lower C-peptide levels emphasizes the role of residual $\beta$-cell function to maintain the nutritional status in patients with T1D. In our study, the correlation with parameters of the exocrine function suggests that even subclinical alterations of pancreatic function may impact on nutritional status.

The pathogenetic mechanisms underlying chronic insufficiency of exocrine pancreatic function in T1D are unknown: the most intuitive reading is the parallel between functional insufficiency and reduced pancreas size. ${ }^{10}{ }^{13-1540}$ Lack of insulinotropic effect on acinar cells secondary to $\beta$-cell depletion was claimed as the primary mechanism for the reduced pancreatic volume, ${ }^{141}$ but the contribution of acinar atrophy was also reported, independently of $\beta$-cell survival. ${ }^{21}$

An alternative view to explain size reduction and associated functional insufficiency is inflammation of the exocrine pancreas and autophagy. Several reports indicate different degrees of leukocyte infiltration of the exocrine pancreas in patients with T1D, including occasional pictures of acute pancreatitis or diffuse mononuclear infiltrates, ${ }^{42}$ dendritic cell and T cells infiltrates, ${ }^{19}$ and mild neutrophils infiltration. ${ }^{1820}$ On the contrary, autoimmunity does not seem to affect the exocrine pancreas, at least as far as it might be reflected by the presence of T1D associated islet cell antibodies, selectively staining islets out of the exocrine background in immunofluorescence on pancreatic cryosections. ${ }^{43}$ In fact, although some autoantibodies specific for exocrine pancreatic antigens have been occasionally reported, ${ }^{44-46}$ none of those findings has been subsequently validated.

Our study has limitations. First, the relatively small number of study participants in each group, due to the commitment to perform the dynamic ${ }^{13} \mathrm{C}$-mixed triglyceride breath test. Second, we were not approved for including children or adolescents in this study and, therefore, we could not study pancreatic exocrine function in individuals during presymptomatic phase of T1D, that is, in individuals with normal glucose tolerance, although positive for circulating islet autoantibodies. In addition, patients with long-standing T1D were diagnosed at a significantly younger age than patients with new-onset T1D, and we cannot exclude that some differences in the pathophysiology may exist between childhood-onset and adult-onset T1D. However, the homogeneous autoantibody status suggests a substantial similarity between the two subgroups included in the study.

In conclusion, our results confirm that exocrine pancreatic impairment is a feature of $\mathrm{T} 1 \mathrm{D},{ }^{47}$ having low fecal elastase- 1 and serum pancreatic amylase and lipase as the most specific markers. Moreover, the evidence of more advanced insufficiency in long-standing disease reflects the chronic nature of this process, while the correlation with residual $\beta$-cell function suggests a close interplay connecting the impairment of the endocrine with that of the exocrine components. Further studies are needed to clarify the exocrine pancreatic contribution to the pathogenesis of T1D and its still unrecognized clinical equivalent.

Acknowledgements We are grateful to San Raffaele Hospital patients and all the volunteers who participated in the study. We wish to thank San Raffaele Hospital staff who assisted with recruitment and study visits.

Contributors ND, GMG, MS, MB and EB conceived and designed the study. ND, $\mathrm{RI}, \mathrm{LF}, \mathrm{AL}$ and AMB performed patients' selection and recruitment, study visits and data collection. AM, AS, AV and ML performed laboratory analyses. MS, ND, $M B$ and EB performed statistical analysis. ND, RI, MS and EB wrote the paper. ND, GMC, MS, MB and EB critically revised the paper. All authors read and approved the submitted version.

Funding This research project was funded through a research grant awarded to Manuela Battaglia, PhD, in 2013 by the Italian Diabetes Society (SID) Research Foundaton SID (Fo.Ri.SID), grant title 'Human type 1 diabetes: a beta-cell or a pancreas-specific disease?', award number N/A.

Competing interests None declared.

Patient consent for publication Not required.

Ethics approval The study was approved by the Ethics Committee of the IRCCS Hospital San Raffaele in Milan on 30 September 2014 (title of the approved study: Type 1 diabetes and exocrine pancreas - DRI-004. Ethics approval ID: 58/INT/2014). Each participant signed an informed consent before screening procedures.

Provenance and peer review Not commissioned; externally peer reviewed.

Data availability statement Data are available on reasonable request. Deidentified participant data analyzed for this study are available on reasonable request from corresponding author Professor Emanuele Bosi (contact: bosi. emanuele@hsr.it. Diabetes Research Institute, San Raffaele Hospital and VitaSalute University. Via Olgettina, 60 - 20132 Milan, Italy).

Supplemental material This content has been supplied by the author(s). It has not been vetted by BMJ Publishing Group Limited (BMJ) and may not have been peer-reviewed. Any opinions or recommendations discussed are solely those of the author(s) and are not endorsed by BMJ. BMJ disclaims all liability and responsibility arising from any reliance placed on the content. Where the content includes any translated material, BMJ does not warrant the accuracy and reliability of the translations (including but not limited to local regulations, clinical guidelines, terminology, drug names and drug dosages), and is not responsible for any error and/or omissions arising from translation and adaptation or otherwise.

Open access This is an open access article distributed in accordance with the Creative Commons Attribution Non Commercial (CC BY-NC 4.0) license, which permits others to distribute, remix, adapt, build upon this work non-commercially, and license their derivative works on different terms, provided the original work is properly cited, appropriate credit is given, any changes made indicated, and the use is non-commercial. See: http://creativecommons.org/licenses/by-nc/4.0/.

\section{ORCID iDs}

Rita Indirli http://orcid.org/0000-0001-5642-0563

Alessandra Mandelli http://orcid.org/0000-0002-6494-7776

Andrea Mario Bolla http://orcid.org/0000-0001-9366-4081

\section{REFERENCES}

1 DiMeglio LA, Evans-Molina C, Oram RA. Type 1 diabetes. Lancet 2018;391:2449-62.

2 Rela M, Reddy MS. Pancreas. In: Gray's anatomy e-book: the anatomical basis of clinical practice. 41. Amsterdam: Elsevier Health Sciences, 2015: 1179-87.

3 Pollard HM, Miller L, Brewer WA. The external secretion of the pancreas and diabetes mellitus. Am J Dig Dis 1943;10:20-3.

4 Domschke W, Tympner F, Domschke S, et al. Exocrine pancreatic function in juvenile diabetics. Am J Dig Dis 1975;20:309-12.

5 Frier BM, Saunders JH, Wormsley KG, et al. Exocrine pancreatic function in juvenile-onset diabetes mellitus. Gut 1976;17:685-91.

6 Frier BM, Faber OK, Binder C, et al. The effect of residual insulin secretion on exocrine pancreatic function in juvenile-onset diabetes mellitus. Diabetologia 1978;14:301-4.

7 Skrha J, Stěpán J, Pacovský V. Serum lipase, isoamylase and pancreatic function test (PFT) in juvenile-onset insulin-dependent diabetes mellitus. Acta Diabetol Lat 1983;20:357-61.

8 Dandona P, Elias E, Beckett AG. Serum trypsin concentrations in diabetes mellitus. BMJ 1978;2:1125. 
9 Dandona P, Freedman DB, Foo Y, et al. Exocrine pancreatic function in diabetes mellitus. J Clin Pathol 1984;37:302-6.

10 Fonseca V, Berger LA, Beckett AG, et al. Size of pancreas in diabetes mellitus: a study based on ultrasound. $B M J$ 1985;291:1240-1.

11 Domínguez-Muñoz JE, Hieronymus C, Sauerbruch T, et al. Fecal elastase test: evaluation of a new noninvasive pancreatic function test. Am J Gastroenterol 1995;90:1834-7.

12 Hardt PD, Hauenschild A, Nalop J, et al. High prevalence of exocrine pancreatic insufficiency in diabetes mellitus. A multicenter study screening fecal elastase 1 concentrations in 1,021 diabetic patients. Pancreatology 2003;3:395-402.

13 Gaglia JL, Guimaraes AR, Harisinghani M, et al. Noninvasive imaging of pancreatic islet inflammation in type $1 \mathrm{~A}$ diabetes patients. $J$ Clin Invest 2011;121:442-5.

14 Williams AJK, Thrower SL, Sequeiros IM, et al. Pancreatic volume is reduced in adult patients with recently diagnosed type 1 diabetes. $J$ Clin Endocrinol Metab 2012;97:E2109-13.

15 Campbell-Thompson ML, Filipp SL, Grajo JR, et al. Relative pancreas volume is reduced in first-degree relatives of patients with type 1 diabetes. Diabetes Care 2019;42:281-7.

16 Campbell-Thompson M, Wasserfall C, Montgomery EL, et al. Pancreas organ weight in individuals with disease-associated autoantibodies at risk for type 1 diabetes. JAMA 2012;308:2337-9.

17 Campbell-Thompson ML, Kaddis JS, Wasserfall C, et al. The influence of type 1 diabetes on pancreatic weight. Diabetologia 2016;59:217-21.

18 Valle A, Giamporcaro GM, Scavini M, et al. Reduction of circulating neutrophils precedes and accompanies type 1 diabetes. Diabetes 2013;62:2072-7.

19 Rodriguez-Calvo T, Ekwall O, Amirian N, et al. Increased immune cell infiltration of the exocrine pancreas: a possible contribution to the pathogenesis of type 1 diabetes. Diabetes 2014;63:3880-90.

20 Vecchio F, Lo Buono N, Stabilini A, et al. Type 1 diabetes TrialNet Study Group, Battaglia M. abnormal neutrophil signature in the blood and pancreas of presymptomatic and symptomatic type 1 diabetes. JCl Insight 2018.

21 Löhr M, Klöppel G. Residual insulin positivity and pancreatic atrophy in relation to duration of chronic type 1 (insulin-dependent) diabetes mellitus and microangiopathy. Diabetologia 1987;30:757-62.

22 Li X, Campbell-Thompson M, Wasserfall CH, et al. Serum trypsinogen levels in type 1 diabetes. Diabetes Care 2017;40:577-82.

23 Kusmartseva I, Beery M, Hiller $\mathrm{H}$, et al. Temporal analysis of amylase expression in control, Autoantibody-Positive, and type 1 diabetes pancreatic tissues. Diabetes 2020;69:60-6.

24 Pezzilli R, Andriulli A, Bassi C, et al. Exocrine pancreatic insufficiency collaborative (EPIC) group. exocrine pancreatic insufficiency in adults: a shared position statement of the Italian association for the study of the pancreas. World J Gastroenterol 2013;19:7930-46.

25 American Diabetes Association. 2. Classification and diagnosis of diabetes: standards of medical care in diabetes-2019. Diabetes Care 2019;42:S13-28.

26 Frulloni L, Falconi M, Gabbrielli A, et al. Italian consensus guidelines for chronic pancreatitis. Digestive and Liver Disease 2010;42:S381-406.

27 Domínguez-Muñoz JE, Iglesias-García J, Vilariño-Insua M, et al. 13C-mixed triglyceride breath test to assess oral enzyme substitution therapy in patients with chronic pancreatitis. Clin Gastroenterol Hepatol 2007;5:484-8.

28 Cesareo R, Attanasio R, Caputo M, et al. Italian association of clinical endocrinologists (AME) and Italian chapter of the American association of clinical endocrinologists (AACE) position statement: clinical management of vitamin D deficiency in adults. Nutrients 2018;10. doi:10.3390/nu10050546. [Epub ahead of print: 27 Apr 2018].

29 Siegmund E, Lohr JM, Schuff-Werner P. The diagnostic validity of non-invasive pancreatic function tests - a meta-analysis. $Z$ Gastroenterol 2004;42:1117-28.

30 Gullo L, Ventrucci M, Tomassetti P. Fecal elastase 1 determination in chronic pancreatitis. Dig Dis Sci 1999;44:210-3.

31 Weaver LT, Amarri S, Swart GR. 13C mixed triglyceride breath test. Gut 1998;43:S13-19.

32 Swislocki A, Noth R, Hallstone A, et al. Secretin-stimulated amylase release into blood is impaired in type 1 diabetes mellitus. Horm Metab Res 2005;37:326-30.

$33 \mathrm{HC} \mathrm{O}$ Kwon Cl, El Haij II EJJ, et al. Low serum pancreatic amylase and lipase values are simple and useful predictors to diagnose chronic pancreatitis. Gut Liver 2017;11:878-83.

34 Lorini R, Cortona L, Scotta MS, et al. Exocrine pancreatic function in children and adolescents with insulin-dependent diabetes mellitus. Diabetes Res Clin Pract 1990;8:263-7.

35 Ludvigsson J. No acute pancreatitis but reduced exocrine pancreatic function at diagnosis of type 1 diabetes in children. Pediatr Diabetes 2019;20:915-9.

36 Keller J, Layer P, Brückel S, et al. 13C-mixed triglyceride breath test for evaluation of pancreatic exocrine function in diabetes mellitus. Pancreas 2014:43:842-8.

37 Cavalot F, Bonomo K, Perna P, et al. Pancreatic elastase-1 in stools, a marker of exocrine pancreas function, correlates with both residual beta-cell secretion and metabolic control in type 1 diabetic subjects. Diabetes Care 2004;27:2052-4.

38 Basu TK, Tze WJ, Leichter J. Serum vitamin A and retinol-binding protein in patients with insulin-dependent diabetes mellitus. Am J Clin Nutr 1989;50:329-31.

39 Jain SK, McVie R, Duett J, et al. The effect of glycemic control on plasma prealbumin levels in type- 1 diabetic children. Horm Metab Res 1993;25:102-4.

40 Gepts W. Pathologic anatomy of the pancreas in juvenile diabetes mellitus. Diabetes 1965;14:619-33.

41 Henderson JR, Daniel PM, Fraser PA. The pancreas as a single organ: the influence of the endocrine upon the exocrine part of the gland. Gut 1981;22:158-67.

42 Foulis AK, Liddle CN, Farquharson MA, et al. The histopathology of the pancreas in type I (insulin-dependent) diabetes mellitus: a 25year review of deaths in patients under 20 years of age in the United Kingdom. Diabetologia 1986;29:267-74.

43 Bottazzo G, Florin-Christensen A, Doniach D. Islet-cell antibodies in diabetes mellitus with autoimmune polyendocrine deficiencies. The Lancet 1974;304:1279-83.

44 Kobayashi T, Nakanishi K, Kajio H, et al. Pancreatic cytokeratin: an antigen of pancreatic exocrine cell autoantibodies in type 1 (insulin-dependent) diabetes mellitus. Diabetologia 1990;33:363-70.

45 Panicot L, Mas E, Thivolet C, et al. Circulating antibodies against an exocrine pancreatic enzyme in type 1 diabetes. Diabetes 1999;48:2316-23.

46 Taniguchi T, Okazaki K, Okamoto M, et al. High prevalence of autoantibodies against carbonic anhydrase II and lactoferrin in type 1 diabetes: concept of autoimmune exocrinopathy and endocrinopathy of the pancreas. Pancreas 2003;27:26-30.

47 Campbell-Thompson M, Rodriguez-Calvo T, Battaglia M. Abnormalities of the exocrine pancreas in type 1 diabetes. Curr Diab $\operatorname{Rep} 2015 ; 15: 79$. 